\title{
The Source of the Anomalous Cathodic Peak During ASV with In Situ Mercury Film Formation in Chloride Solutions
}

\author{
Melissa A. Nolan and Samuel P. Kounaves* \\ Department of Chemistry, Tufts University Medford, Massachusetts 02155, USA
}

Received: April 1, 1999

Final version: June 10, 1999

\begin{abstract}
In situ mercury film depositions at a glassy carbon electrode at various concentrations of sodium chloride or hydrochloric acid were performed. In the chloride concentration range of 0.001 to $0.5 \mathrm{M}$, an anomalous cathodic peak is observed during the anodic scan when performing square wave voltammetry. This phenomenon has previously been attributed to the formation of mercury(I) chloride (calomel) on the electrode surface. Cyclic voltammetry indicated that electrochemically generated calomel, which forms due to the oxidation of the mercury film in solutions with greater than $0.001 \mathrm{M} \mathrm{Cl}^{-}$, is reversible and is reduced to elemental mercury during cathodic polarization of the electrode. It is proposed that the cathodic peak is a result of the calomel which forms after $\mathrm{Hg}(\mathrm{O})$ is oxidized to $\mathrm{Hg}$ (I) by $\mathrm{Hg}$ (II) ions and subsequent reaction of $\mathrm{Hg}(\mathrm{I})$ with chloride ions. This insoluble nonelectrochemically generated calomel is formed under open circuit conditions and, not being reduced during the cathodic polarization, is reduced at more anodic potentials. The most stable and reproducible responses of this system for ASV of $\mathrm{Cd}^{2+}$ and $\mathrm{Pb}^{2+}$ is obtained when the mercury is removed from the electrode surface by electrochemical oxidation at the end of each anodic scan.
\end{abstract}

Keywords: In situ, Mercury film, Calomel, Stripping voltammetry

\section{Introduction}

In situ mercury film formation has been often used as a procedure for the deposition of mercury during anodic stripping voltammetry (ASV) [1-11], but its utility has been hampered by the appearance of an anomalous cathodic peak during the anodic scan $[2,3,5-8,11]$. This cathodic peak occurs in a chloride medium and has been attributed to the formation of insoluble calomel $\left(\mathrm{Hg}_{2} \mathrm{Cl}_{2}\right)$ on the mercury surface. The formation of calomel is detrimental to the surface of the mercury film and the resulting cathodic peak can interfere with the stripping peaks. The stripping peak becomes masked and can not be quantified as a result of the anomalous cathodic peak that occurs during the cathodic scan. It has been shown that using a solution containing either $\mathrm{KSCN}$ [7] or $1.0 \mathrm{M} \mathrm{Cl}^{-}$[5] the cathodic peak can be effectively eliminated.

Recently, two papers [3, 11] have also addressed the appearance of this cathodic peak and have given possible explanations for its presence. Jagner et al. [3] concluded that the cathodic peak was probably due to the calomel on the electrode surface that is formed by the open circuit nonelectrochemical reaction:

$$
\mathrm{Hg}^{0}+\mathrm{Hg}(\mathrm{II}) \rightarrow \mathrm{Hg}_{2}{ }^{2+}+2 \mathrm{Cl}^{-} \rightarrow \mathrm{Hg}_{2} \mathrm{Cl}_{2}(\mathrm{~s})
$$

They proposed that the "... appearance of the cathodic peak might be due to a crystalline reorientation in the potential interval of -0.85 to $-0.6 \mathrm{~V}$, the crystal arrangement at lower electrode potentials being much less reversible than that at the higher potentials."

However, their paper did not address the issue that the oxidation and reduction of calomel is very reversible.

Zakharchuk et al. [11] concluded that two soluble compounds are formed on the electrode in chloride solutions: 1) calomel, which forms a reversible redox couple and is reduced to metallic mercury during the cathodic polarization and 2) another insoluble compound which appears during anodic polarization of the mercury coated electrode in solutions containing chloride ions when the mole ratio $\mathrm{HCl} / \mathrm{Hg}^{2+}$ of the solution is less than $10^{4}$. They then further concluded that the cathodic peak is due to the latter compounds and not calomel. However, this paper did not address or reference the research and results reported by Jagner [3].

During a recent extensive investigation into the appearance of this anomalous cathodic peak while using in situ mercury film formation [5], we showed that the cathodic peak occurs only when the chloride concentration is between 0.001 and $0.5 \mathrm{M}$ and that it is independent of the substrate (glassy carbon, platinum, or iridium). In this paper, we report on the results of using a $\mathrm{HCl} / \mathrm{Hg}^{2+}$ mole ratio of less than $10^{4}$, as suggested by Zakharchuk [11], for a solution containing $0.8 \mathrm{mM} \mathrm{Hg}^{2+}$ The results of our experiments suggest an alternative explanation for the cathodic peak that integrates the conclusions of the two previous authors.

\section{Experimental}

\subsection{Apparatus}

Cyclic voltammetry (CV), linear scan voltammetry (LSV), and square-wave voltammetry (SWV) experiments were performed with an EG\&G PAR Model 273 potentiostat/galvanostat (EG\&G PAR, Princeton, NJ) interfaces to a DEC p420-SX microcomputer using Model 270 software (EG\&G PAR). All voltammetric experiments were performed in a three electrode cell consisting of a $3 \mathrm{~mm}$ glassy carbon electrode (BAS, West Lafayette, IN), a reference electrode and a Pt wire counter electrode. Two different reference electrodes were used. For solutions with a chloride concentration greater than $1.0 \mathrm{M}$, a $\mathrm{Ag} / \mathrm{AgCl}$ $(3 \mathrm{M} \mathrm{NaCl})$ reference electrode (BAS, West Lafayette, IN), was used. For all other solutions, a polyurethane solid state reference electrode [12] was used. All potentials are reported relative to the $\mathrm{Ag} / \mathrm{AgCl}(3 \mathrm{M} \mathrm{NaCl})$ reference electrode.

\subsection{Reagents}

All solutions were prepared with $18 \mathrm{M} \Omega \mathrm{cm}$ deionized water from a Barnstead Nanopure system (Barnstead Co., Dubuque, 
IA). Metal solutions were prepared with $99.999+\% \mathrm{Cd}\left(\mathrm{NO}_{3}\right)_{2}$ (Aldrich), $\mathrm{Pb}\left(\mathrm{NO}_{3}\right)_{2}$ (Aldrich), and $\mathrm{Hg}\left(\mathrm{NO}_{3}\right)_{2}$ (Johnson Matthey). Trace metal grade $\mathrm{HCl}$ and $\mathrm{HNO}_{3}$ (Fisher Scientific) were used. All other solutions were prepared with ACS grade reagents.

\subsection{Experimental Conditions}

In situ mercury film formation was carried out in a solution containing $0.8 \mathrm{mM} \mathrm{Hg}^{2+}, 0.01 \mathrm{M} \mathrm{HNO}_{3}$, and $100 \mathrm{ppb} \mathrm{Cd}^{2+}$ and $\mathrm{Pb}^{2+}$. Unless otherwise indicated, the SWASV analyses were performed using the following parameters: initial potential $E_{\mathrm{i}}=-1.0 \mathrm{~V}$, final potential $E_{\mathrm{f}}=0.5 \mathrm{~V}$, deposition time $t_{\mathrm{d}}=120 \mathrm{~s}$, frequency $f=60 \mathrm{~Hz}$, pulse amplitude $E_{\mathrm{sw}}=25 \mathrm{mV}$, and step height $\Delta E_{\mathrm{s}}=2 \mathrm{mV}$.

\section{Results and Discussions}

Zakharchuk et al. [11] suggested that the mole ratio of $\mathrm{HCl} / \mathrm{Hg}^{2+}$ plays an important role in the appearance of the cathodic peak. They determined that the cathodic peak appeared when the mole ratio of $\mathrm{HCl} / \mathrm{Hg}^{2+}$ was less than $10^{4}$. In recent work by Nolan and Kounaves [5], it was shown that the cathodic peak appears when the chloride concentration is between 0.001 and $0.5 \mathrm{M}$. That work was performed in a solution containing $0.8 \mathrm{mM} \mathrm{Hg}^{2+}$ and $0.01 \mathrm{MHNO}_{3}$, with the chloride concentration being varied by the addition of sodium chloride. For a more accurate comparison to Zakharchuk's results, the experiments reported here were performed as in [5] but with the chloride concentration being varied by the addition of $\mathrm{HCl}$. The cathodic peak still occurred in the chloride concentration range of 0.001 to $0.5 \mathrm{M}$ when the final potential was set to $0.5 \mathrm{~V}$. In solutions containing $0.8 \mathrm{mM} \mathrm{Hg}^{2+}$, but with $0.5 \mathrm{M}<\left[\mathrm{Cl}^{-}\right]<4.0 \mathrm{M}$ (i.e., $\left.625<\mathrm{HCl} / \mathrm{Hg}^{2+}<5000\right)$, no cathodic peak was observed. This is in contradiction to the results of Zakharchuk et al. [11] for mercury solutions containing less than $0.3 \mathrm{mM} \mathrm{Hg}^{2+}$.

Zakharchuk et al. proposed that the cathodic peak was not due to the formation of calomel because calomel forms a reversible redox pair. [11] To test this, the oxidation and reduction of calomel was investigated using cyclic voltammetry, with potential control of the electrode always maintained. The solutions consisted of $0.8 \mathrm{mM} \mathrm{Hg}^{2+}$ and $0.01 \mathrm{M} \mathrm{HNO}_{3}$ with various chloride concentrations. The cyclic voltammetry parameters were: initial potential $E_{\mathrm{i}}=-1.0 \mathrm{~V}$, vertex potential $E_{\mathrm{v}}=0.5 \mathrm{~V}$, and the scan rate $v=0.05 \mathrm{~V} / \mathrm{s}$. Three scans were performed in each solution. For $\left[\mathrm{Cl}^{-}\right]<0.001 \mathrm{M}$, the mercury was oxidized off of the surface as $\mathrm{Hg}^{2+}$. For $\left[\mathrm{Cl}^{-}\right]>0.001 \mathrm{M}$, the mercury was oxidized to calomel as indicated by the gray film remaining on the electrode surface. The cyclic voltammograms for $\left[\mathrm{Cl}^{-}\right]=0.1 \mathrm{M}$ (where the cathodic peak occurs) and for $\left[\mathrm{Cl}^{-}\right]=1.0 \mathrm{M}$ (no cathodic peak occurs) are shown in Figure 1. These cyclic voltammograms clearly demonstrate that the reduction and oxidation reactions of calomel at both chloride concentrations are reversible. The voltammograms also indicate that the calomel formed by the oxidation of mercury is reduced back to $\mathrm{Hg}^{0}$ during the cathodic scan. Thus, during the cathodic polarization (application of $-1.0 \mathrm{~V}$ ) this calomel was easily reduced to $\mathrm{Hg}^{0}$ and was not responsible for the cathodic peak. However, if potential control was discontinued in the $0.1 \mathrm{M}$ chloride solution, a cathodic peak occurred at approximately $-0.45 \mathrm{~V}$ in the anodic scan, indicating that the cathodic peak was due to a nonelectrochemical reaction. In the $1.0 \mathrm{M}$ chloride

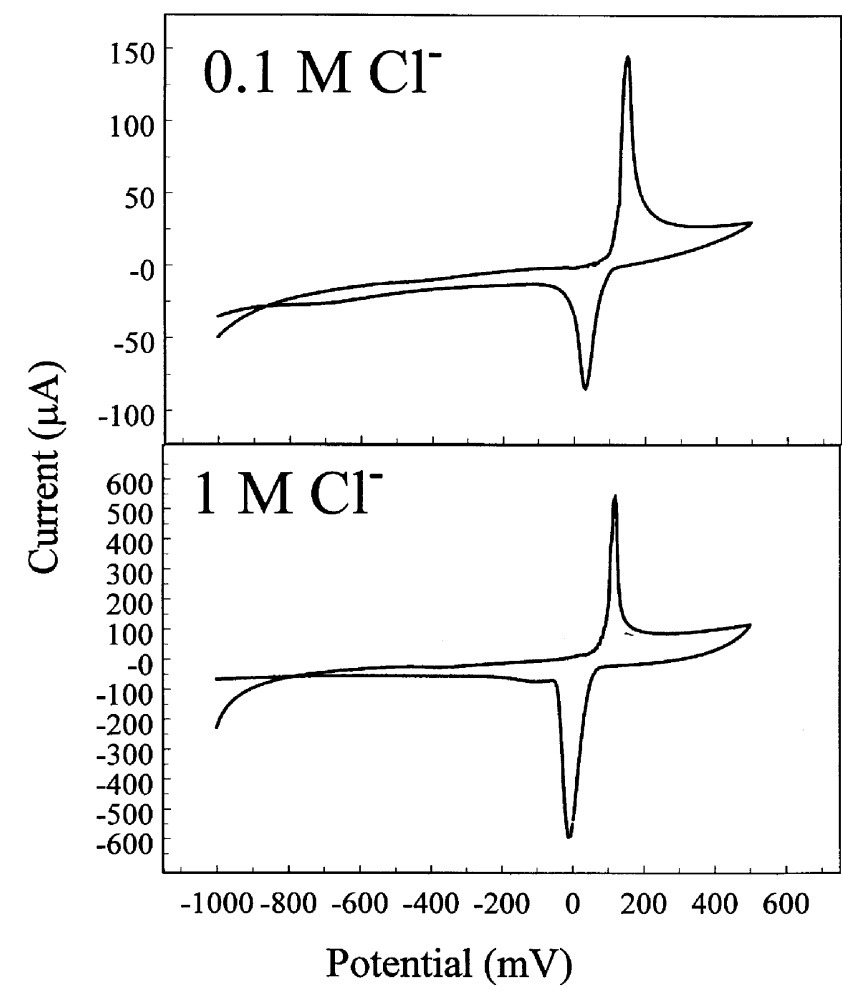

Fig. 1. Cyclic voltammograms in $0.8 \mathrm{mMHg}^{2+}, 0.01 \mathrm{MHNO}_{3}$ with $0.1 \mathrm{M} \mathrm{NaCl}$ or $1.0 \mathrm{M} \mathrm{NaCl}$ with a GCE. CV parameters: $E_{\mathrm{i}}=-1.0 \mathrm{~V}$, $E_{v},=0.5 \mathrm{~V}$, and $v=0.05 \mathrm{~V} / \mathrm{s}$. Potential control of the electrode was always maintained. Second scan is shown.

solution no difference in the cyclic voltammograms was observed when the open circuit potential was allowed.

Under open circuit conditions Jagner [3, 13] proposed that calomel forms according to Reaction 1 . The results obtained by Jagner et al. [3] demonstrated that the cathodic peak was due to the presence of calomel on the mercury surface. Two observations in particular indicate that the cathodic peak is due to the formation of calomel. 1) The stoichiometry of the cathodic peak is in good agreement with the reduction of calomel. A 1:1 stoichiometric relationship between the magnitude of the cathodic peak and the amount of calomel formed was indicated. 2) The microscopic observations revealed that when crystalline calomel and a mercury film were present on the surface and an anodic scan was performed, at approximately $-0.8 \mathrm{~V}$ the calomel crystallites were reduced to mercury droplets. The results also indicate that $\mathrm{Hg}^{0}$ must be on the electrode surface for the calomel to be reduced to mercury droplets. When only crystalline calomel was present on the electrode surface no cathodic peak was observed.

Taking into account the results reported in these three publications $[3,5,11]$ reasonably leads one to the conclusion that there are two forms of calomel produced in a chloride medium, one by electrochemical and the other by nonelectrochemical pathways. Electrochemically generated calomel occurs via the oxidation of $\mathrm{Hg}^{0}$ in solutions containing $\left[\mathrm{Cl}^{-}\right]>0.001 \mathrm{M}$ and is then easily reduced during cathodic polarization back to $\mathrm{Hg}^{0}$. On the other hand, nonelectrochemically generated calomel is formed under open circuit conditions according to Reaction 1 and is not reduced during the cathodic polarization, but is reduced during the anodic scan at potentials between -0.6 and $-0.3 \mathrm{~V}$. Thus, the cathodic peak is due to the reduction of the 
nonelectrochemically generated calomel to $\mathrm{Hg}^{0}$. This means that the elimination of Reaction 1 should prevent the formation of nonelectrochemically generated calomel and thus eliminate the cathodic peak.

There are several ways to prevent the formation of nonelectrochemically generated calomel on the electrode surface. It has been shown [5] that Reaction 1 occurs only when $0.001 \mathrm{M}<\left[\mathrm{Cl}^{-}\right]<0.5 \mathrm{M}$. For $\left[\mathrm{Cl}^{-}\right]<0.001 \mathrm{M}$, the $\mathrm{Hg}^{0}$ film can be oxidized and removed from the electrode substrate by setting the final potential to $0.5 \mathrm{~V}$. Thus, Reaction 1 cannot occur because no $\mathrm{Hg}^{0}$ remains on the electrode surface. However, great care must be taken to insure that chloride contamination (resulting in $\left[\mathrm{Cl}^{-}\right]>0.001 \mathrm{M}$ ) does not occur from such sources as reference electrodes. Reaction 1 will also not occur in solutions containing $>0.5 \mathrm{M} \mathrm{Cl}^{-}$[5] or in solutions containing KSCN [7], a mercury complexing agent.

For $0.001 \mathrm{M}<\left[\mathrm{Cl}^{-}\right]<0.5 \mathrm{M}$ both nonelectrochemically and electrochemically generated calomel are present on the electrode surface. During the cathodic polarization the latter form of calomel is reduced to $\mathrm{Hg}^{0}$ while the nonelectrochemically generated calomel is not reduced until anodic scan potentials between $-0.6 \mathrm{~V}$ and $-0.3 \mathrm{~V}$ are reached. Jagner et al. [3] proposed that the irreversibility of calomel in the potential range of $-1.15 \mathrm{~V}$ to $-0.85 \mathrm{~V}$ might be due to calomel crystal reorientation because the orientation of calomel changes with electrode polarization. However, the crystalline orientation should also depend on how the calomel is formed. The electrochemically generated calomel may be in a more suitable orientation to be reduced during the cathodic polarization. When the potential is scanned anodically the nonelectrochemically generated calomel reorientates on the electrode surface. When a favorable orientation is obtained (between $-0.6 \mathrm{~V}$ and $-0.3 \mathrm{~V}$ ), the nonelectrochemically generated calomel is reduced to $\mathrm{Hg}^{0}$ and the cathodic peak occurs.

The effects of applying an oxidizing potential the mercury were further investigated by monitoring the response of the ASV stripping peaks for $100 \mathrm{ppb} \mathrm{Cd}^{2+}$ and $\mathrm{Pb}^{2+}$ in a solution containing $0.8 \mathrm{mM} \mathrm{Hg}^{2+}, 0.01 \mathrm{M} \mathrm{HNO}_{3}$, and with either $\left[\mathrm{Cl}^{-}\right]=0 \mathrm{M}$ or $\left[\mathrm{Cl}^{-}\right]=1.0 \mathrm{M}$. Two different final potentials were tested, $0.5 \mathrm{~V}$ to insure oxidation and $-0.1 \mathrm{~V}$ to avoid oxidation of the mercury film. With no chloride present, oxidation at $-0.1 \mathrm{~V}$ results in the mercury film being completely stripped off of the electrode. With $\left[\mathrm{Cl}^{-}\right]=1.0 \mathrm{M}$, the mercury is oxidized and disproportionates to give the electrochemically generated form of calomel, which then remains on the electrode surface. Figure 2 shows the effects on the peak stripping current of $\mathrm{Cd}^{2+}$ and $\mathrm{Pb}^{2+}$ with $(\mathrm{O}, \mathbf{0})$ and without $(\square, \boldsymbol{\square})$ oxidation of the mercury film, respectively, for thirty consecutive runs. The relative standard deviations for the thirty consecutive runs are given in Table 1. For either $\left[\mathrm{Cl}^{-}\right]=0 \mathrm{M}$ and $\left[\mathrm{Cl}^{-}\right]=1.0 \mathrm{M}$, when the mercury was oxidized, a stable response for $\mathrm{Cd}^{2+}$ and $\mathrm{Pb}^{2+}$ was obtained after the first or second scan and maintained thereafter. When the mercury was not oxidized, a stable signal was not obtained until approximately after the first ten runs. For the subsequent 20 runs however, the relative standard deviation did show substantial improvement.

\section{Conclusions}

It appears reasonable from the data that two types of calomel form on the electrode surface during in situ mercury film formation, electrochemically generated calomel and nonelectro-

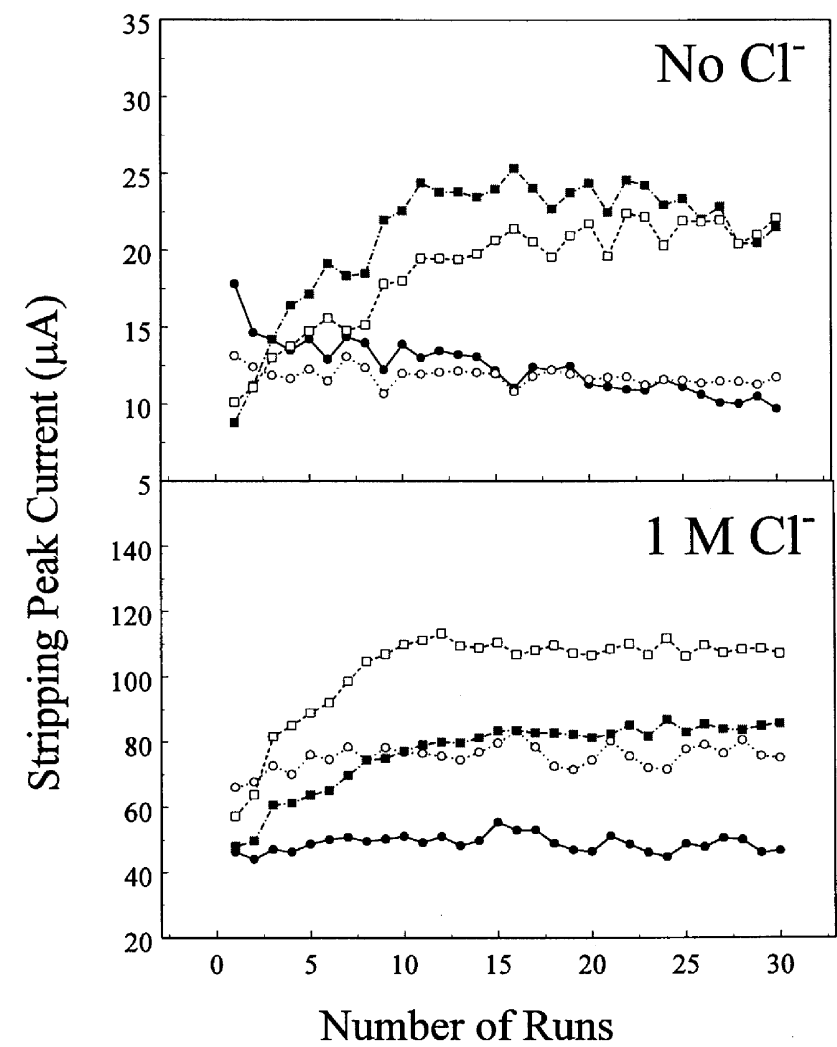

Fig. 2. The effects on the peak stripping currents for in situ mercury deposition with a GCE in $0.8 \mathrm{mM} \mathrm{Hg}^{2+}, 0.01 \mathrm{MHNO}_{3}$, with $\left[\mathrm{Cl}^{-}\right]=0$ or $1.0 \mathrm{M}$, for $100 \mathrm{ppb} \mathrm{Cd}^{2+}$ and $\mathrm{Pb}^{2+}$ with $(\bigcirc, \mathbf{O})$ and without $(\square, \mathbf{\square})$ oxidation of the mercury film, respectively, for thirty consecutive runs.

Table 1. The relative standard deviations for thirty consecutive runs in a solution containing $0.8 \mathrm{mM} \mathrm{Hg}^{2+}, 0.01 \mathrm{MHNO}_{3}, 100 \mathrm{ppb} \mathrm{Cd}^{2+}$ and $\mathrm{Pb}^{2+}$ while varying the final potentials (2nd row). The deviations in parentheses are those for the last twenty runs.

\begin{tabular}{llllll}
\hline & {$\left[\mathrm{Cl}^{-}\right]=0 \mathrm{M}$} & & & \multicolumn{2}{l}{$\left[\mathrm{Cl}^{-}\right]=1.0 \mathrm{M}$} \\
\cline { 2 - 3 } & -0.1 & & & -0.1 & 0.5 \\
\hline $\mathrm{Cd}^{2+}$ & $3.2(1.10$ & 0.84 & & $6.3(0.39)$ & 0.87 \\
$\mathrm{~Pb}^{2+}$ & $3.3(1.2)$ & 2.1 & & $4.9(0.56)$ & 0.87 \\
\hline
\end{tabular}

chemically generated calomel. The calomel is electrochemically formed from the oxidation of mercury in solutions with $\mathrm{Cl}^{-}$ concentrations $>0.001 \mathrm{M}$. This calomel is reduced to $\mathrm{Hg}^{0}$ during cathodic polarization of the electrode and is also responsible for the film that remains on the electrode surface for $\mathrm{Cl}^{-}$concentrations greater than $0.001 \mathrm{M}$. The nonelectrochemically generated calomel forms under open circuit conditions when $\mathrm{Hg}^{0}$ remains on the electrode surface at $\mathrm{Cl}^{-}$concentrations $<0.5 \mathrm{M}$ or when $\mathrm{Hg}^{2+}$ ions are not complexed and free to react. The nonelectrochemically generated calomel is responsible for the appearance of the cathodic peak. The cathodic peak is detrimental in stripping analysis procedures because it can mask and interfere with the stripping peak. When performing ASV with an in situ mercury electrode, the formation of the nonelectrochemically generated calomel should be avoided at all cost. This can be easily achieved by using a solution containing $\mathrm{KSCN}$ or $1.0 \mathrm{M} \mathrm{Cl}^{-}$. Both of these species complex the $\mathrm{Hg}^{2+}$ 
ions so they can not react with the mercury film or with the nonelectrochemically generated calomel. The most stable and reproducible ASV signals are obtained when the mercury is oxidized at the end of the scan.

\section{Acknowledgements}

This work was supported in part by grants from the Environmental Protection Agency through the Northeast Hazardous Substance Research Center at NJIT, and the National Science Foundation (CHE-9256871). The authors would also like to thank group members (Rosemary Feeney, Sandie Tan, Vladislav Tarasov, John Birtles, and Brian Comeau) for their valuable assistance and discussions.

\section{References}

[1] T.M. Florence, J. Electroanal. Chem. 1970, 27, 273.

[2] W. Frenzel, Anal. Chim. Acta 1993, 273, 123.

[3] D. Jagner, E. Sahlin, L. Renman, Anal. Chem. 1996, 68, 1616.

[4] S. Komorsky-Lovric, M. Lovric, A.M. Bond, Anal. Chim. Acta 1992, 258, 299.

[5] M.A. Nolan, S.P. Kounaves, Anal. Chem. 1999, 71, 1176.

[6] M. Wojciechowski, J. Balcerzak, Anal. Chem. 1990, 62, 1325.

[7] M. Wojciechowski, J. Balcerzak, Anal. Chim. Acta 1991, 249, 433.

[8] H.P. Wu, Anal. Chem. 1994, 66, 3151.

[9] H.P. Wu, Anal. Chem. 1996, 68, 1639.

[10] A.S. Baranski, Anal. Chem. 1987, 59, 662.

[11] N.F. Zakharchuk, K.Z. Brainina, Electroanalysis 1998, 10, 379.

[12] M. Nolan, S. Tan, S. Kounaves, Anal. Chem. 1997, 69, 1244.

[13] D. Jagner, Anal. Chem. 1978, 50, 1924. 